between intrauterine growth inhibition and $\mathrm{NO}$ activity in late preterm infants.

Methods Newborns with gestational age of 34-36 weeks and birth weight of 1200-2600 g were allocated to two groups: 21 infants with normal growth parameters were classified as first group and 15 intrauterine growth restricted (IUGR) infants were included in second group. Gestational age was assessed by the last menstrual period and confirmed by scale of Ballard et al. Plasma and urine samples of infants were collected on the first day of life. Nitric oxide concentration quantified by principle based on using the enzyme Nitrate Reductase to convert nitrate to nitrite.

Results Mean plasma nitrat products were higher $(\mathrm{p}<0.05)$ in second group infants $(42.6 \pm 7.3 \mu \mathrm{M} / \mathrm{L})$, than in first group (59 \pm 7.3 $\mu \mathrm{M} / \mathrm{L})$. Statistically true rising $(\mathrm{p}<0.01)$ was noted in urine NO level of IUGR infants, where mean NO level was 1.4 times higher compared with first group newborns.

Conclusion Intrauterine growth retardation is associated with high NO production of infants at an early neonatal period, which might indicate intrauterine activation of NO sources of fetus.

\section{EVALUATION OF PEDIATRIC TESTES AFTER SURGERY BY LASER DOPPLER AND WHITE LIGHT SPECTROSCOPY}

doi:10.1136/archdischild-2012-302724.1043

${ }^{1} \mathrm{~J}$ de Laffolie, ${ }^{2} \mathrm{R}$ Freudenberger, ${ }^{2} \mathrm{~S}$ Turial, ${ }^{2} \mathrm{~V}$ Engel, ${ }^{2} \mathrm{~F}$ Schier. ${ }^{1}$ General Pediatrics and Neonatology, University of Gießen, Giessen; 2Department of Pediatric Surgery, University of Mainz, Mainz, Germany

Aim To evaluate testes after unilateral orchiopexy Laser Doppler and white light spectroscopy and compare microcirculation with contralaterat testis and healthy controls.

Methods A combination of the laser Doppler (determination of blood flow) and white light spectroscopy (determination of oxygen saturation and hemoglobin amount) is used to determine microcirculation at two different depth levels non-invasively. Patients were recruited after unilateral orchiopexy. Controls were age-matched boys without relevant disease. Ethical approval was obtained.

Results 99 patients were included after unilateral orchiopexy at the age of 3.5 years (+-2.9 years). $65 \%$ underwent surgery after their second birthday. Follow-up was at median 2.5 years after surgery (3months - 10.5 years). Controls were 29 boys at the age of median 6.3 years ( 3 month-13 years). There was no significant difference in age between both groups.

85 patients were examined on the operated side with laser doppler and white light spectroscopy. Significant higher flow and velocity were found contralateral ( $\mathrm{p}=0.041, \mathrm{p}=0.022)$. Surprisingly, when comparing the contralateral testes in patients after orchiopexy with healthy controls, flow and velocity were significantly higher in the healthy controls $(p<0.001)$, even though this testis was previously not operated on.

Conclusion After orchiopexy, expected differences were found in microcirculation between the operated and contralateral testes or healthy controls. Surprisingly, the contralateral testes' microcirculation was also significantly different from controls. This is probably not a consequence of surgery alone, but more likely a common problem of both testes in the affected patients.

\section{EVALUATING MODE OF DELIVERY OF IRON OR IRON AND ZINC ON IRON STATUS AND IRON STRESS MARKERS}

doi:10.1136/archdischild-2012-302724.1044

${ }^{1} \mathrm{U}$ Dhingra, ${ }^{2} \mathrm{~A}$ Pradhan, ${ }^{3} \mathrm{VP}$ Menon, ${ }^{1} \mathrm{~A}$ Dutta, ${ }^{4} \mathrm{P}$ Dhingra, ${ }^{1} \mathrm{R}$ Black, ${ }^{4} \mathrm{~S}$ Madhesiya, ${ }^{4} S$ Gupta, 'S Sazawal. 'International Health, Johns Hopkins Bloomberg School of Public Health, Baltimore, MD, USA; ${ }^{2} R H N$, Indian Council of Medical Research, New Delhi; ${ }^{3}$ Center for Micronutrient Research, Clinical Trials and Operational Research in Maternal and Child Health (CMR-CTORMCH), Annamalai; ${ }^{4}$ Center for Public Health Kinetics, New Delhi, India
Background Iron deficiency remains a major nutritional problem among infants and young children in India. The tablet/syrup-based programs do have logistic, supply and compliance challenges. Tablet/Syrup may have increased risk of free iron in blood, oxidative stress and risk of infections.

Objective In a community based RCT we evaluated 3 approaches of iron delivery for impact on iron status, pro and anti-inflammatory interleukins and non-transferrin bound iron (NTBI) with 30 day intervention

Methods 300 children 22-34 months were enrolled and randomized to receive either iron fortified biscuit $(n=74)$, iron tablet $(n=77)$, iron+ zinc tablet $(\mathrm{n}=74)$ or placebo $(\mathrm{n}=75)$ for 30 days.

Results Delivery of iron through biscuit showed better impact on hemoglobin (Mean Diff: 0.60; $95 \%$ CI: 0.16-1.04) and other hematological markers like RDW, MCV and $\mathrm{MCH}$ at 30 day post supplementation. The NTBI estimation at day 1 and 30 post supplementation, 3 hours after ingestion of supplement dose; an indicator of oxidative stress caused by dose after iron status repletion, suggested the lowest burden with biscuit $(2 \%)$ and a higher burden with supplements (6-7\%). At day 30 there was no effect on interleukins in the biscuit group; increase in IL-6/IL10 in iron tablet, increase in IL-8/ IL10 in iron+zinc tablet group.

Conclusion Providing iron through fortified biscuits was as efficient and effective in improvement of iron status and hematological markers as iron tablets. Biscuit was marginally better for NTBI or immune response. The benefit of using biscuits needs to be evaluated in a larger community based effectiveness program.

\section{LONGITUDINAL STUDIES OF BREAST MILK ZINC TRANSFER TO APPROPRIATE- AND SMALL-FOR-GESTATIONAL-AGE, PREDOMINANTLY BREAST FED, BANGLADESHI INFANTS}

doi:10.1136/archdischild-2012-302724.1045

MM Islam. Centre for Nutrition and Food Security, ICDDR, B, Dhaka, Bangladesh

Background In developing countries, information is limited on concentration of breastmilk zinc, total amount of zinc transferred to infants through breast milk and whether zinc transfer through breastmilk differs among appropriate-for-gestational-age (AGA) and smallfor-gestational-age (SGA) infants at different times post-partum.

Aims To measure breastmilk and zinc transfer through breastmilk, using deuterium "dose-to-mother" technique, in mothers of AGA and SGA infants.

Methods Forty-six mother-infant pairs were recruited (20 AGA and 26 SGA infants). Each mother-infant pair was studied three times, at 4, 12 and 24 weeks post-partum. In each round, two-week studies of breast milk transfer were carried out, using the deuterium oxide "dose-to-mother" technique. Breast milk samples were collected on days 1 and 5 of each round for milk zinc concentration.

Results Mean $( \pm S D)$ birth weight and length were $3.02 \pm 0.2 \mathrm{~kg}$ and $48.2 \pm 1.2 \mathrm{~cm}$ for AGA infants and $2.34 \pm 0.20 \mathrm{~kg}$ and $46.2 \pm 1.1 \mathrm{~cm}$ for SGA infants. Breast milk intake increased gradually with time postpartum, and was marginally greater among AGA infants only at 4 weeks $(p=0.06)$. Breast milk zinc concentration decreased when the infants grow $(p<0.001)$, but differed between neither of the groups. Zinc transfer through breast milk decreased significantly with age in both the groups, but did not differ $(p<0.001)$.

Conclusions Breast milk zinc concentration among Bangladeshi mothers was similar to values reported for women from wealthier countries, and there was no relationship between infant birth weight category and milk zinc concentration or milk zinc transfer.

\section{IODINE STATUS IN PRESCHOOL CHILDREN AND EVALUATION OF MAJOR DIETARY IODINE SOURCES: A} GERMAN EXPERIENCE

doi:10.1136/archdischild-2012-302724.1046 
SA Johner, T Remer. DONALD Study, University of Bonn, Research Institute of Child Nutrition, Dortmund, Germany

Purpose Even mild iodine deficiency may negatively affect cognitive performance, especially at a young age. Our aim was to investigate iodine status in very young children and to assess the importance of iodized salt in processed foods as an example for a country with voluntary salt iodization.

Methods 24-h urinary iodine excretion (UIE) as a marker of iodine intake was measured in 378 repeatedly collected 24 -h urine samples (2003-2010) of $2213-<6$ year old participants of the DONALD Study. Parallel 3-d weighed dietary records and measurements of urinary sodium excretion provided data on the daily consumption of the most important iodine providers in the children's diet (iodized salt, milk, fish, meat and eggs). Time trends of UIE (2003-2010) and contributions of the different food groups were analysed by using linear mixed-effects regression models.

Results Median UIE of $71 \mu \mathrm{g} / \mathrm{d}$ in boys and $65 \mu \mathrm{g} / \mathrm{d}$ in girls, corresponding to an iodine intake of 82 and $75 \mu \mathrm{g} / \mathrm{d}$, respectively (assumption: $15 \%$ non renal iodine losses) was below the WHO intake recommendations of $90 \mu \mathrm{g} / \mathrm{d}$. Milk, salt and egg intake were significant predictors of UIE; milk and salt together accounted for $>80 \%$ of iodine supply. Between 2003 and 2010, UIE decreased significantly by approximately $1 \mu \mathrm{g} /$ year. The contribution of salt intake to UIE decreased from 03-06 to 07-10.

Conclusion In countries where salt is a major iodine provider, already modest decreases in the iodized proportion of salt used in processed foods may relevantly impair iodine status even in preschool children.

\section{VITAMIN B12 LEVELS OF 0-24 YEARS-0LD PEOPLE IN KONYA, TURKEY}

doi:10.1136/archdischild-2012-302724.1047

${ }^{1} \mathrm{~F}$ Akin, ${ }^{2 \mathrm{H}}$ Yavuz, ${ }^{3} \mathrm{~S}$ Bodur, ${ }^{4} \mathrm{~A}$ Kiyici. ${ }^{1}$ Konya Training and Research Hospital; ${ }^{2}$ Pediatrics; ${ }^{3}$ Public Health, Konya University, Meram Medical Faculty; "Biochemistry, Selcuk University, Selcuklu Medical Faculty, Konya, Turkey

Background It was reported that levels of vitamin B12 show racial differences. Therefore we wanted to determine normal serum levels of vitamin B12 in Konya region, Turkey.

Methods Totally 1109 samples of which 54 were cord bloods and the rest were 1055 healthy $0-24$ years-old subjects who admitted to primary health centers. Vitamin B12 measurement was done at the biochemistry laboratory of Selcuk University Meram Medical Faculty with the original Beckman kits (Beckman Coulter, CaliforniaUSA) by chemiluminesans method.

Results The reference levels obtained for vitamin B12 at $\mathrm{P}_{2.5}-\mathrm{P}_{97.5}$ range were; $127-606 \mathrm{pg} / \mathrm{ml}$ for girls and $127-576 \mathrm{pg} / \mathrm{ml}$ for boys. Reference level for the total study group was $127-590 \mathrm{pg} / \mathrm{ml}$.

Conclusion The values reported in other studies are higher than our results. Vitamin B12 levels vary among countries. Using reference ranges of other populations may lead to inaccurate results. Therefore normal levels which will be valid for that population should be obtained.

\section{INFANTICIDE, 'AFTER-BIRTH ABORTION' AND RECENT PHILOSOPHICAL CONTROVERSIES CONCERNING THE VALUE OF NEWBORN LIFE}

doi:10.1136/archdischild-2012-302724.1048

J Wyatt. Institute for Womens Health, UCL Institute of Child Health and Great Ormond Street Hospital for Children, London, UK

The Journal of Medical Ethics recently published an article by philosophers Guibilini and Minerva (1) arguing that the intentional killing of newborn infants was justified if the continued existence of the child represented 'an unbearable burden for the psychological health of the woman or for her already existing children', as well as if there were excessive economic burdens or disability. They argued that both fetuses and newborns do not have the same moral status as actual persons, since they lack self-awareness. Hence the destruction of a newborn life is morally justified if it is in the best interests of existing people. Although the position of Guibilini and Minerva is supported by several other prominent philosophers, including Michael Tooley and Peter Singer, I will argue that it is fatally flawed.

a) It is incoherent to argue that conscious self-awareness is necessary criterion for life to have intrinsic value,

b) The argument strikes at the heart of the central belief enshrined in the Universal Declaration of Human Rights, that all human beings possess inherent moral worth solely in virtue of their membership of the human species, and irrespective of their functional abilities,

c) Since self-awareness as an agent probably does not start to appear before 18 months of age, and may not be secure until the fourth year of life, the argument imperils not just newborns but a large proportion of the paediatric population!

Reference Giubilini, A, Minerva F, J Med Ethics epub 3 Feb 2012.

\section{BURDEN OF CHRONIC EXPOSURE TO DIFFICULT ETHICAL DECISIONS ON CARE CAREGIVERS IN SWISS NICUS}

doi:10.1136/archdischild-2012-302724.1049

N Hauser, HU Bucher, JC Fauchere. Division of Neonatology, Univ. Hospital Zurich, Zurich, Switzerland

Aim This study explored the degree of burden of chronic exposure to difficult ethical decisions on health care providers (HCP) in Swiss level III NICUs.

Methods 224 questionnaires were sent to neonatologists and nurses of all level III NICUs. Demographical information, attitudes and behaviours towards ethical decisions, and the impact of those decisions on HCP's health and private life were collected.

Results 52 neonatal physicians and 60 nurses $(27$ men, 85 women, overall response rate 50\%) took part in this survey. Altogether, $78 \%$ stated that the ethical dilemmas/decision-making represent a burden to them. $87 \%$ experience this burden as momentary. In nearly $40 \%$, this burden affects private life; in another $48 \%$ it occasionally impact on private life. $25 \%$ of physicians and $10 \%$ nurses suffer from exhaustion. Most of the respondents find relief from stress through their hobbies (70\%) and discussions with family members and friends (74\%). The most used coping strategies are debriefings after ethical discussions, team discussions and support from hospital pastoral care. Professional moderation of debriefings was only rarely available (10\%).

Conclusion Chronic exposure to stressful situations represents a burden for the majority of HCP working in NICU environment. Exhaustion is far more frequent than physical and psychosomatic symptoms. Hobbies and social contacts are important coping strategies. Given the potential of chronic burden to not only affect health of caregiver but also to shape the attitudes of caregivers in daily neonatal intensive care medicine, the importance of team debriefings and support under professional guidance cannot be stressed enough.

\section{ETHICAL DILEMMA IN NEONATOLOGY}

doi:10.1136/archdischild-2012-302724.1050

SA Ahmed, A Arasu. Neonatology, Luton \& Dunstable Hospital NHS Foundation Trust, Luton, UK

Aim To ascertain parents' attitude, knowledge and awareness of the type of Surfactant used in the Neonatal unit to treat Respiratory Distress Syndrome and their religious perspective. 